in 1970. There was worldwide interest in the Swann Report, some agreeing, some disagreeing, but all wanting to know the outcome of what looked like a serious attempt to understand and possibly limit the spread of antibiotic resistances among bacteria.

Alas for good intentions and hopes, however: what legislation brought into existence in 1973 was not the powerful committee recommended by Swann but a joint subcommittee of the Committee on Safety of Medicines and the Veterinary Products Committee. The two parent committees were concerned mainly with applications from pharmaceutical firms for product licences and test certificates. In practice, the Veterinary Products Committee consulted the Joint SubCommittee on Anti-microbial Substances a great deal while the Committee on Safety of Medicines used it very little. Occasionally others also consulted the Joint Sub-Committee on Anti-microbial Substances on matters affecting the use of antimicrobials as pesticides, food additives, and decontaminants. Practically all the subcommittee's work, however, was in advising the Veterinary Products Committee on applications to introduce new antimicrobials or variations of old ones. Attempts by the subcommittee to secure information from the pharmaceutical industry about the amounts of antibiotics used in human and veterinary medicine and in animal husbandry ended in frustration. Time was never found to legislate to make it compulsory to disclose the information requested, even in confidence. With the encouragement of the Joint Sub-Committee on Anti-microbial Substances, individual members did valuable work on a personal basis with pharmaceutical firms, specifically in helping to clear up ambiguities and shortcomings in applications submitted. But the subcommittee itself could not contact firms direct because it was in a subordinate position; it was there to advise, not to decide, and appeals against decisions of either of the parent committees might have been complicated by direct contacts if these had led to matters agreed between applicants and the joint subcommittee being viewed differently by the parent committees.

The main weaknesses of the Joint Sub-Committee on Anti-microbial Substances, however, were twofold. Firstly, it had no powers to review the effects of antibiotics already approved. Secondly, it had no resources to commission field studies on a sufficient scale to monitor resistances or to have laboratory findings checked when applications to introduce a new antimicrobial agent or a new use of an existing one left room for doubt about the validity of the conclusions presented. Despite evidence gathered by the subcommittee, some firms continued to advertise in the farming press in a way that clearly encouraged farmers to have certain drugs given to their animals either by pressing their vets to try them or, more probably, securing supplies by their own ingenuity. Doubt remained about how serious the problem of antibiotic resistance really was and whether the best solution was to mount educational campaigns against overuse of antibiotics by both doctors and vets.

Dissatisfied with the uncertain value of its own considerable and careful work-and the lack of powers and resources to do its intended job-the Joint Sub-Committee on Anti-microbial Substances made detailed proposals for its reform and for new terms of reference. After long discussions these were submitted to ministers, whose quick and dismaying reaction was to disband the subcommittee. Admittedly, they added two wellqualified and eminently suitable microbiologists to the Veterinary Products Committee. But that hardly meets the real requirement, well stated by $\mathbf{J} R$ Walton's letter in the Veterin- ary Record" as, "A small group of people with expertise in agriculture, public health, veterinary medicine, bacterial genetics, and clinical medicine." Walton considered that such a group would need access to laboratory facilities; would need to be provided with data on antibiotic use and prevalence of antibiotic resistance; and should be able to develop a close working relationship with the pharmaceutical industry.

Walton is pessimistic in concluding that such a proposal will "never get past first base." Certainly the drastic response of ministers to the subcommittee's own proposals justifies pessimism, especially with the present shortage of Government spending on real investment and especially on medical education and preventive medicine. But there are perhaps some possibilities. The laboratories of the Public Health Laboratory Service and the Veterinary Service at Weybridge supplied the Joint Sub-Committee on Anti-microbial Substances with essential evidence of multiple resistances in salmonellas again spreading by an epidemic in calves, the resistances being induced by trimethoprim. Thus the laboratory skills and interest are not lacking. Individual microbiologists also have added valuable evidence in papers published in this and other journals during the past few years. Surely the public interest and concern must also be that of the pharmaceutical industry. It should not be beyond the capacity and good will of those concerned to get together a group of people to work out the details of a better approach than that embodied in the Joint Sub-Committee on Anti-microbial Substances-one that would justify the expenditure required to supplement what already exists in the Public Health Laboratory Service and at Weybridge.

The ministers have killed their quango. No doubt they will win the love of the Treasury for their further "act of madness" - a familiar, well-justified phrase. Now they should shake their consciences and look for the right way to supplement their unwisely withheld resources. Antibiotic resistances are worth serious and continuing study lest by their spread they extinguish the usefulness of therapeutic antibiotics.

1 foint Committee on the Use of Antibiotics in Animal Husbandry and Veterinary Medicine. London: HMSO, 1969:12.16 and 12.17 (Cmnd 4190; Swann Report.)

2 Walton JR. Advising on antimicrobials. Vet Rec 1981;108:366.

\section{Painful iceberg}

Every doctor knows (or should know) that the most common cause of recurrent abdominal pain is the spastic colon or irritable-bowel syndrome. But how common is this syndrome in the general population? And do all sufferers complain to their doctors, or is there an iceberg of undiagnosed disease? Until recently no figures had been available to answer these questions, but now a survey carried out mainly in Bristol has gone some way to filling the gap. ${ }^{1}$ A total of 301 apparently healthy adults of both sexes and all ages answered a detailed questionnaire, mainly about abdominal pain and bowel habits. No fewer than one-fifth admitted to recurrent abdominal pain in the previous year. In two-thirds of these (14\% of the total) the pain was relieved by defecation, which strongly suggests that it was colonic. Similar pains may be felt by people with colitis or carcinoma of the colon, but these serious diseases 
can hardly have been present in so many persons in good general health, particularly as they also denied rectal bleeding. Moreover, these uncomplaining sufferers very often admitted to other symptoms characteristic of the spastic-colon type of irritable-bowel syndrome, ${ }^{2}$ such as abdominal distension, a feeling of incomplete evacuation, and a change in bowel habit when an episode of pain began. In the $7 \%$ of subjects whose pains were not relieved by defecation they were often related to food. Possibly they were due to "functional dyspepsia" or even undiagnosed peptic ulcers.

The frequency of constipation in the British population has long been common knowledge and is to non-sufferers an occasion for mirth. In the Bristol study painless constipation (defined as frequent straining at stool) was admitted by $6 \%$ of those questioned and was clearly related to age. Less predictably, a further $4 \%$ admitted to painless diarrhoea, which may be a variant of the irritable-bowel syndrome. Finally, no fewer than $14 \%$ said that they suffered from proctalgia fugax. ${ }^{3}$ Proctalgia fugax can probably be caused by spasm in the rectosigmoid region, ${ }^{4}$ and no less than one-third of its victims also suffered from recurrent abdominal pain of colon-spasm type.

Altogether nearly one-third of the 301 persons interviewed admitted to recognisable functional gut syndromes. Perhaps the most striking statistic to emerge from these studies, however, is that only one-quarter of these had consulted a doctor about their gastrointestinal tract in the past year. ${ }^{1}$ It seems that the irritable-bowel syndrome must join hypertension, gall stones, and many other disorders of our society as an iceberg disease.

Doctors may count themselves lucky that so many potential patients prefer to suffer in silence, but they should also ponder the implications of these findings. For a start, they challenge the popular medical belief that the irritable-bowel syndrome is an intestinal response to neurotic anxiety. This is hard to reconcile with the finding that most sufferers do not bother their doctors. Perhaps those who do seek medical advice are the ones with the most severe symptoms, but it is just as likely that they are the ones most worried by their symptoms. This would explain the large proportion of anxious patients with the irritable-bowel syndrome. The first line of treatment is explanation and reassurance ${ }^{5}$; sometimes that is all that is required.

That leaves perhaps the most difficult but also the most intriguing question. Why do so many "normal" people have symptoms of dysfunction of the gut and, especially, of the colon. Advocates of the fibre hypothesis have an answer ready made, but they need to prove that the irritable-bowel syndrome is less common in communities eating a high-fibre diet. Certainly, bran and other bulking agents help in many cases, but not all, and in this condition there is a large placebo effect with any treatment.

Perhaps food allergy or other more subtle effects of diet play some part and psychological factors cannot be discounted altogether. After all, in many ways the irritable-bowel syndrome is analogous to migrainc: it may be just as disabling, and both diseases are easy to diagnose if, and only if, a careful history is taken.

1 Thompson WG, Heaton KW. Functional bowel disorders in apparently healthy people. (jastrocnterology 1980;79:283-8.

2 Manning AP, Thompson WG, Heaton KW, Morris AF. Towards positive diagnosis of the irritable bowel. Br Med f 1978; ii:653-4.

3 Thompson WG, Heaton $\mathrm{KW}$. Proctalgia fugax. $7 \mathrm{R}$ Coll Physicians Lond $1980 ; \mathbf{1 4}: 2.47-8$

"Harvey RF. Colonic motility in proctalgia fugax. Lancet 1979;ii:713-4.

Anonymous. Management of the irritable bowel. Lancet 1978;ii:557-8.

\section{Prognosis of Crohn's disease}

How should patient and physician react to a diagnosis of Crohn's disease ? Is the prognosis bleak or merely somewhat depressing? Four recent papers have summarised the experiences of two physicians and four surgeons in Birmingham who have treated 513 patients with Crohn's disease from 1944 to 1976. Their overall conclusion" is that "an optimistic attitude to the eventual outcome is justified."

No treatment strategy is generally agreed for Crohn's disease. In Birmingham the approach has been conservative medical treatment combined with, or followed by, aggressive surgical resection. The principles of treatment were bed rest at times of exacerbation, haematinics and liberal blood transfusion, avoidance of excessive dietary fibre, and surgery for complications. The surgeons removed as little bowel as possible but their indications for operation included not only obstruction but also persistent ill health or the presence of fistulas. The medical treatment was so conservative that only one-third of patients ever received steroids, only one in 20 received sulphasalazine, and even fewer received azathioprine. Only one patient was given parenteral nutrition.

The first paper reviewed 174 patients who had Crohn's disease diagnosed before 1956, the survivors being followed up for a mean of $27 \cdot 8$ years. ${ }^{1}$ Only seven patients escaped surgery: one in three had only a single operation, but the average was $2 \cdot 5$. The most frequent definitive procedure was resection of the distal ileum with or without a right hemicolectomy, but $15 \%$ underwent panproctocolectomy with ileostomy. The risk of surgery dropped from $11 \%$ a year in the first five years after diagnosis to $6 \%$ a year two decades later. Recurrence rates after surgery were unaffected by whether it was the first or the fifth operation, but recurrence was more common in younger patients. Just over one-third of patients developed at least one fistula, most of which responded to surgery. By the end of the study $13 \%$ had their small intestine resected to $200 \mathrm{~cm}$ or less, but one-quarter of these died postoperatively. Fortyfive per cent became deficient in vitamin $\mathrm{B}_{12}$, and $8 \%$ developed osteomalacia. Renal disease (obstruction of the right ureter, $6 \%$; renal calculi, 5\%; enterovesical fistulas, 3\%; and renal amyloid, $2 \%$ ) was relatively common. Six patients developed dementia, three of whom were under 62 at the time of their death.

The second paper ${ }^{2}$ reviewed the incidence and causes of death in 513 patients followed up from one to 35 years. The death rate was twice that expected in normal people. The greatest risk was in the youngest patients, falling as time from diagnosis increased. Most of the extra deaths were due to causes directly attributable to Crohn's disease or its complications; $10 \%$ of the 513 patients died from Crohn's disease itself.

The third paper showed a clear association between Crohn's disease and carcinoma of the gastrointestinal tract. ${ }^{3}$ Thirty-one tumours developed in the 513 patients. Though there was no excess of tumours outside the gastrointestinal tract the risk of gastrointestinal malignancy was increased over threefold. Tumours developed in the oesophagus and stomach (which were macroscopically free of Crohn's disease) and in the colon (particularly if there was extensive colonic disease).

The final paper ${ }^{4}$ reviewed 227 patients with Crohn's disease restricted to the terminal ileum at the time of presentation; some patients in the earlier review were included and the follow-up was from 1944 to 1978. Ninety per cent of these patients had surgery, but half had only one operation. Those who needed surgery soon after the onset of symptoms had the 